
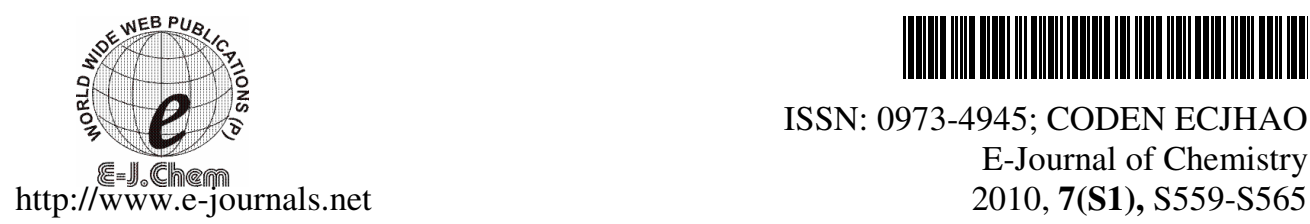

ISSN: 0973-4945; CODEN ECJHAO

E-Journal of Chemistry

2010, 7(S1), S559-S565

\title{
Rhodamine-Sulphuric Acid \\ -A New Visualization Reagent for the Determination of Sucralose by HPTLC
}

\author{
MOHD.IDRIS $^{\S^{*}}$, SEEMA SRIVASTAVA ${ }^{\S}$, \\ T.R.BAGGI ${ }^{\#}$, S.K.SHUKLA and A.K.GANJOO ${ }^{\S}$ \\ ${ }^{\S}$ Central Forensic Science Laboratory, Ministry of Home Affairs \\ Govt. of India, Ramanthapur, Hyderabad 500 013, India \\ \#Department of Forensic Science, University College of Science \\ Osmania University, Hyderabad 500 007, India \\ Central Forensic Science Laboratory, Ministry of Home Affairs \\ Govt.of India, Chandigarh, India \\ md_idris3@yahoo.com
}

Received 10 March 2010; Accepted 25 May 2010

\begin{abstract}
Sucralose a UV-visible inactive compound was separated on silica gel plate without any plate treatment prior to analysis, derivatized with rhodamine - sulphuric acid reagent and detected densitometrically at $456 \mathrm{~nm}$ as olive green band. With this reagent sucralose also shows golden yellow fluorescence at $366 \mathrm{~nm}$. Two new solvent systems i.e. chloroform: methanol: toluene (v/v 5:3.5:1.5) (solvent system-I) and chloroform: ethanol: benzene (v/v 5:3:2) (solvent system-II) were developed and giving $R_{\mathrm{f}}$ values of 0.62 and 0.45 respectively. The method was found to be sensitive with good limit of detection (LOD) for two solvent systems. The method imparts specificity to the method as at $456 \mathrm{~nm}$ sucralose only gives olive green color spots where as other artificial sweeteners did not show any response to this reagent, where as carbohydrates gives black color spots. Similarly sucralose gives golden yellow fluorescence at $366 \mathrm{~nm}$ which is not given by any other artificial sweetener. The method was highly reproducible with relative standard deviation (RSD) $\leq 3 \%$ $(n=3)$ and was applied for the determination of sucralose in different matrices like cola drinks, lemon juices, sugar free sweets, tabletop sweeteners etc.
\end{abstract}

Key words: Sucralose, Rhodamine-sulphuric acid, HPTLC, Beverages, Sweets.

\section{Introduction}

Sucralose, 1,6-dichloro-1,6-dideoxy- $\beta$ - $D$-fructofyranosyl-(2 $\rightarrow 1$ )-4-chloro-4-deoxy- $\alpha$ - $D$ galactopyranoside) (Figure 1) is made by substituting 3 hydroxyl groups of sucrose with 
chlorine atoms. Sucralose is approximately 600 times as sweet as sucrose. It is stable under heat and over a broad range of $\mathrm{pH}$ concentration and can be used in baking or in products that require a longer shelf life. Sucralose does not promote tooth decay. The European Union's scientific committee on food, U.S food and drug administration (FDA) approved its use in 1998. The acceptable daily intake is in general has been agreed to be $15 \mathrm{mg} / \mathrm{kg} / \mathrm{day}$. It also has been approved by the regulatory agencies of many countries for use in numerous food and pharmaceutical preparations.

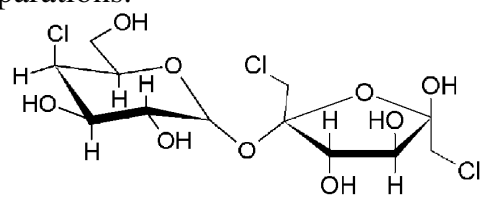

Figure 1. Sucralose structure

Sucralose was analyzed by RP-HPLC methods employing refractive index detection ${ }^{1-3}$, pre-column derivatized HPLC by treatment with $p$-nitrobenzoyl chloride (PNBCL) ${ }^{4}$, simultaneous determination with other non-nutritive sweeteners in foods by HPLC/ESI-MS ${ }^{5}$, HPLC-ELSD ${ }^{6}$ capillary electrophoresis ${ }^{7}$ and isotope dilution LC/MS/MS ${ }^{8}$. All these methods are tedious and require complicated sample preparation and are expensive. Compared to all these methods planar chromatographic methods offer simple, fast, simultaneous multi sample handling and cost effective method. Sucralose was detected by reagent free derivatization on amino-phase TLC plates $^{9-11}$, even though these methods are simple but the amino-phase TLC plates are three to four time costly than normal silica gel coated plates and also for derivatization we are suppose to heat the plate for 20 minutes at $190{ }^{\circ} \mathrm{C}$. Sucralose was separated also on silica gel coated TLC plates and detected by derivatization with aniline diphenylamine orthophosphoric acid / naphthol sulfuric acid ${ }^{12}$. However these methods require pretreatment of plates by impregnation with dipotassium hydrogen phosphate solution $(0.1 \mathrm{M})$.

This paper describes a simple method for separation of sucralose on silica gel plate without any plate pretreatment and detected by post derivatization by rhodamine-sulfuric acid in visible as well as fluorescence mode with good sensitivity.

\section{Experimental}

Sucralose was supplied by Virchows laboratory (Hyderabad, India), where as sucrose and dextrose was purchased from Qualigens (Mumbai, India). All solvents used were of analytical grade obtained from S.d. fine chemicals (Mumbai, India). Ultra pure water was produced by a synergy system (Millipore, Schwalbach, Germany). Cola drinks, lemon juices, tabletop sweeteners and dietetic sweets were purchased from local market. Rhodamine 6G (Basic Red 1), sulphuric acid and ethanol were purchased from Merck, India.

\section{Apparatus}

For the chromatographic investigations, Camag, Switzerland equipment comprising of a TLC Scanner II with a computer system and winCats Software V. 1.4.2, ATS4 application device, a twin-trough chamber, a TLC Immersion Device III, Camag TLC Plate heater were used. Aluminum HPTLC plates coated with silica gel $\mathrm{F}_{254}(20 \mathrm{~cm} \times 10 \mathrm{~cm})$ were supplied by Merck (Germany).

\section{Procedure}

Commercially available tabletop sweeteners and dietetic sweets shows the sucralose content as $70 \mathrm{mg} / \mathrm{g}$ and $15 \mathrm{mg} / 10 \mathrm{~g}$ respectively. The samples were ground and a representative aliquot $1 \mathrm{~g}$ of dietetic sweets and $10 \mathrm{mg}$ of tabletop sweetener respectively were transferred 
to $10 \mathrm{~mL}$ volumetric flasks and suspended in methanol made up till the mark while shaking. Extraction of sucralose was performed in an ultrasonic bath for $20 \mathrm{~min}$. Samples were filtered through a Whatmann filter paper No.4 before application to the stationary phase.

Commercially available cola drinks, lemon juices, sweets did not contain sucralose and were used for spiking with sucralose (cola drinks and lemon juices were spiked at $100 \mathrm{mg} \mathrm{L}^{-1}$, $80 \mathrm{mg} \mathrm{L}^{-1}, 60 \mathrm{mg} \mathrm{L}^{-1}$ and sweets were spiked at $1 \mathrm{~g} \mathrm{~kg}^{-1}, 1.5 \mathrm{~g} \mathrm{~kg}^{-1} \& 2 \mathrm{~g} \mathrm{~kg}^{-1}$ ). Cola drinks and lemon juices $(1 \mathrm{~mL}$ each) were diluted 1:1 with methanol where as sweets were homogenized and $1 \mathrm{~g}$ was extracted with $10 \mathrm{~mL}$ of methanol. Cola drinks and lemon juices were ultrasonicated for $10 \mathrm{~min}$ where as sweets samples were ultrasonicated for $20 \mathrm{~min}$ and filtered through a Whatmann filter paper No.4 before application to the HPTLC plate. For calibration, a $0.1 \mathrm{mg} \mathrm{mL}^{-1}$ working solution of sucralose in methanol was prepared.

\section{Application}

For determination the solutions were applied to the plates as $4 \mathrm{~mm}$ bands by spraying with the Automatic TLC Sampler 4 (ATS4), enabling a maximum of 21 tracks to be applied to one $20 \mathrm{~cm} \times 10 \mathrm{~cm}$ HPTLC plate(distance from lower edge $15 \mathrm{~mm}$, distance from the left side $10 \mathrm{~mm}$,distance between bands $9 \mathrm{~mm}$ ). For calibration, $0.5-2.5 \mu \mathrm{L}$ of the standard solution (50-250 ng per band) was applied to the plate five times. The dietetic sample solutions (tabletop sweetener and dietetic sweets) were applied as $1 \mu \mathrm{L}$ and $2.5 \mu \mathrm{L}$ respectively. For determination of limit of detection 0.1 to $1 \mu \mathrm{L}$ of the $10 \mathrm{ng} \mu \mathrm{L}^{-1}$ standard solution was applied to the plate. Whereas $1 \mu \mathrm{L}$ of spiked samples of cola drinks, lemon juices and sweets were applied to the plate for recovery studies.

\section{Chromatography}

Aluminum plates were developed in a $20 \mathrm{~cm} \times 10 \mathrm{~cm}$ twin-trough chamber (TTC). Silica gel plates were developed with the mobile phase, Chloroform: methanol: toluene $(5: 3.5: 1.5)$ (solvent system-1) and chloroform: ethanol: benzene (5:3:2) (solvent system-2). The development distance was $75 \mathrm{~mm}$ from the application point and the migration time was approximately $20 \mathrm{~min}$ for both solvent systems.

\section{Derivatization}

Rhodamine-sulfuric acid solution was prepared by adding $3 \mathrm{~mL}$ of sulfuric acid to $20 \mathrm{~mL}$ of $0.25 \%$ ethanolic solution of rhodamine with continuous stirring. The reagent was stable for at least for two hours at room temperature.

Post-chromatographic derivatization of sucralose on silica gel was performed with the TLC Immersion Device III using a dipping speed of $3 \mathrm{~cm} \mathrm{~s}^{-1}$ and dipping time of $1 \mathrm{~s}$, followed by heating of the plate on the TLC plate heater III at $120{ }^{\circ} \mathrm{C}$ for $3 \mathrm{~min}$. Sucralose derivative was visible as olive green spots where as carbohydrates appeared as black spots against light yellow background. With the reagent sucralose and carbohydrates gave spots of golden color and red fluorescence at $366 \mathrm{~nm}$ respectively. The fluorescence spots were visualized at $366 \mathrm{~nm}$ (reflectance mode) in the Digitostore 2 documentation system consisting of the reprostar 3 illuminator and the powershot G2 digital camera (Canon, Tokyo, Japan).

\section{Evaluation and documentation}

Densitometric evaluation with the TLC Scanner 3 was performed via peak area by fluorescence measurement at $366 \mathrm{~nm}$ and by absorbance measurement at $456 \mathrm{~nm}$ in the calibration range 50 to $250 \mathrm{ng}$ sucralose / band. Plate images were documented by use of the Digitostore2 documented system under illumination at $366 \mathrm{~nm}$ and in the visible range, all in the reflectance mode. The data obtained were processed with winCATS software, version 1.4.2. 


\section{Results and Discussion}

Performing selective derivatization of sucralose on the plate is a strong feature of planar chromatography because all chromatographic runs were derivatized simultaneously followed, usually by a few minutes of heating. Sucralose was separated on silica gel $60 \mathrm{~F}_{254}$ HPTLC plates without any impregnation of TLC plates prior to analysis using chloroform: methanol : toluene $(5: 3.5: 1.5)$ and chloroform : ethanol : benzene $(5: 3: 2)$ by volume giving $\mathrm{R}_{\mathrm{f}}$ values of 0.45 and 0.62 respectively. Sucrose, dextrose and other matrices did not interfere with the analysis of sucralose despite the simple sample preparation. This method can be used selectively for analysis of sucralose in the presence of other artificial sweeteners. The reagent did not form any derivative with other artificial sweeteners like saccharin, aspartame and cyclamate. A great advantage of the proposed HPTLC method is simple sample preparation unlike the use of a solid phase extraction step used for HPLCMS-MS ${ }^{8}$ or HPLC-ELSD ${ }^{6}$.

Visualization was enabled densitometrically by post-chromatographic derivatization of sucralose with rhodamine-sulfuric acid reagent (Figure 2). Sucralose gives olive green spot (Figure 3A) and its identity was confirmed by recording visible spectrum (Figure 4).With this reagent sucralose also gives golden fluorescence at $366 \mathrm{~nm}$ where as carbohydrates gives red florescence (Figure 3B).The optimum wavelength for absorbance measurement in the visible range was found to be $456 \mathrm{~nm}$. Figure 5 shows a typical calibration curve for sucralose after derivatization with rhodamine-sulfuric acid and absorbance measurement at $456 \mathrm{~nm}$.

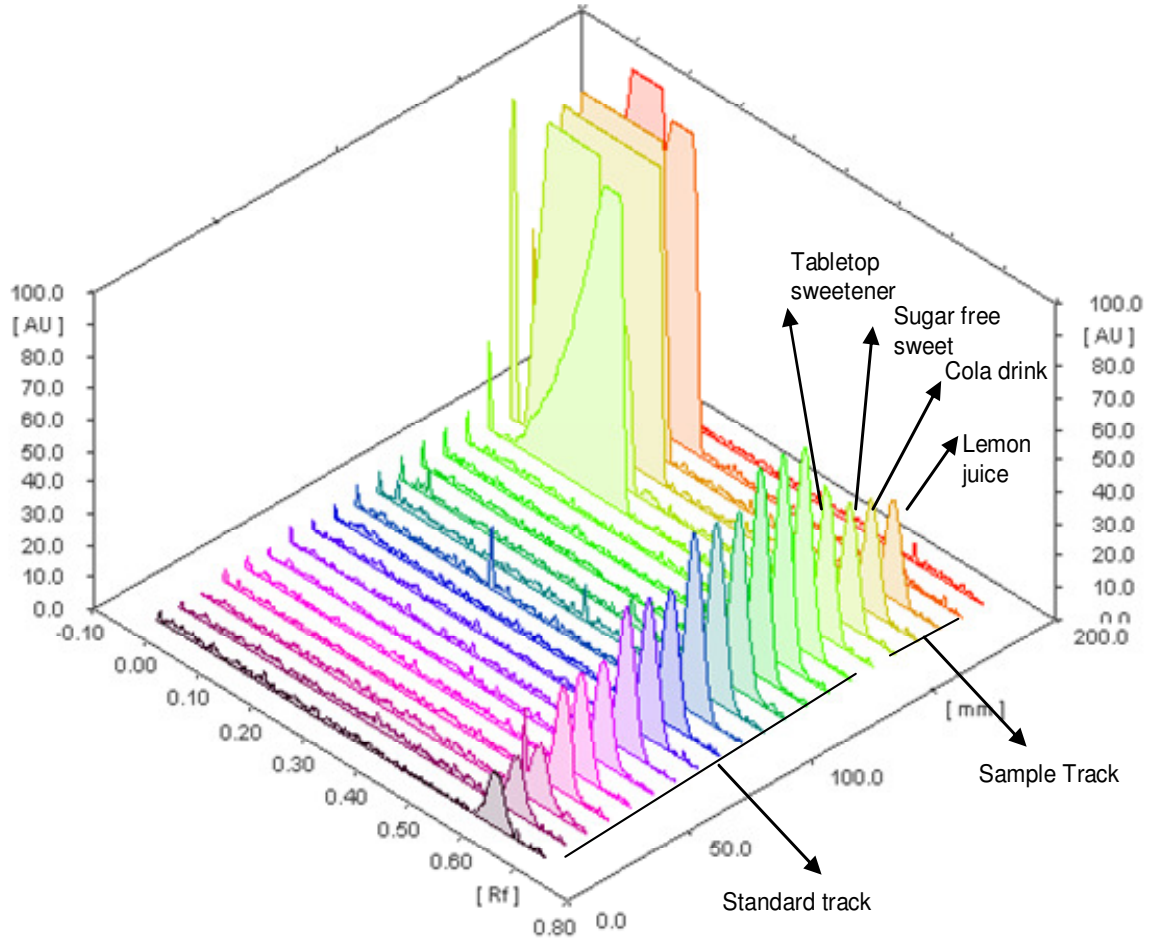

Figure 2. Absorbance measurement of sucralose at $456 \mathrm{~nm}$ after derivatization with the rhodamine-sulfuric acid reagent; tracks 1-15 sucralose standards tracks 16, 17, 18, 19 are of Cola drink, Lemon juice, Sugar free sweet and Tabletop sweetener respectively (Solvent system-I) 


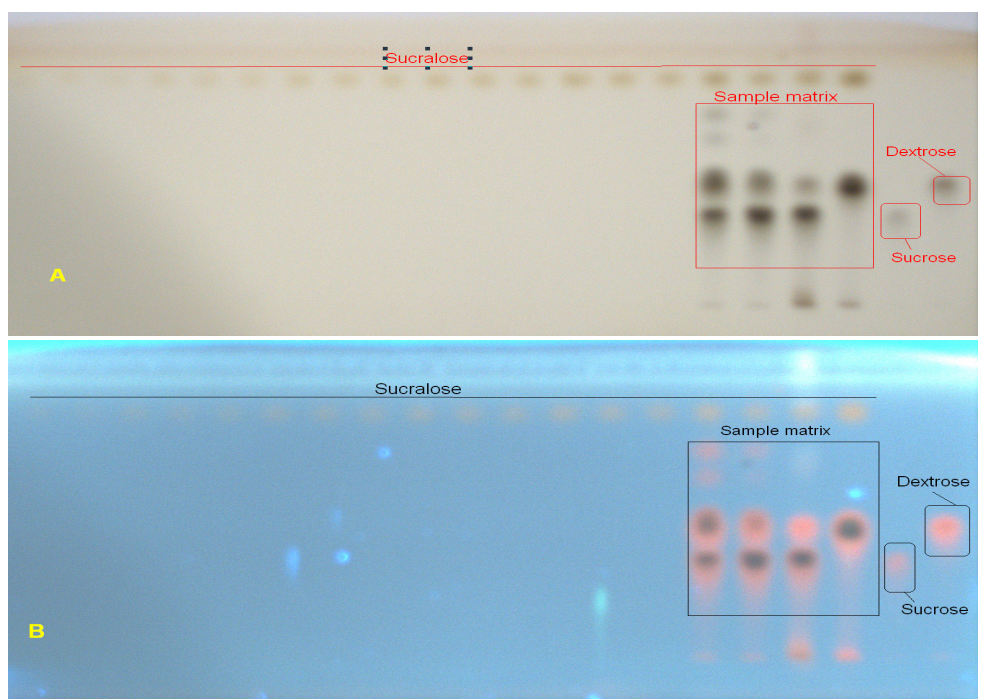

Figure 3. Documentation of plate images (illuminated in reflectance mode) obtained during quantification of sucralose. (A) $456 \mathrm{~nm}$ (B) $366 \mathrm{~nm}$ after derivatization with rhodamine-sulfuric acid (Solvent system-I)

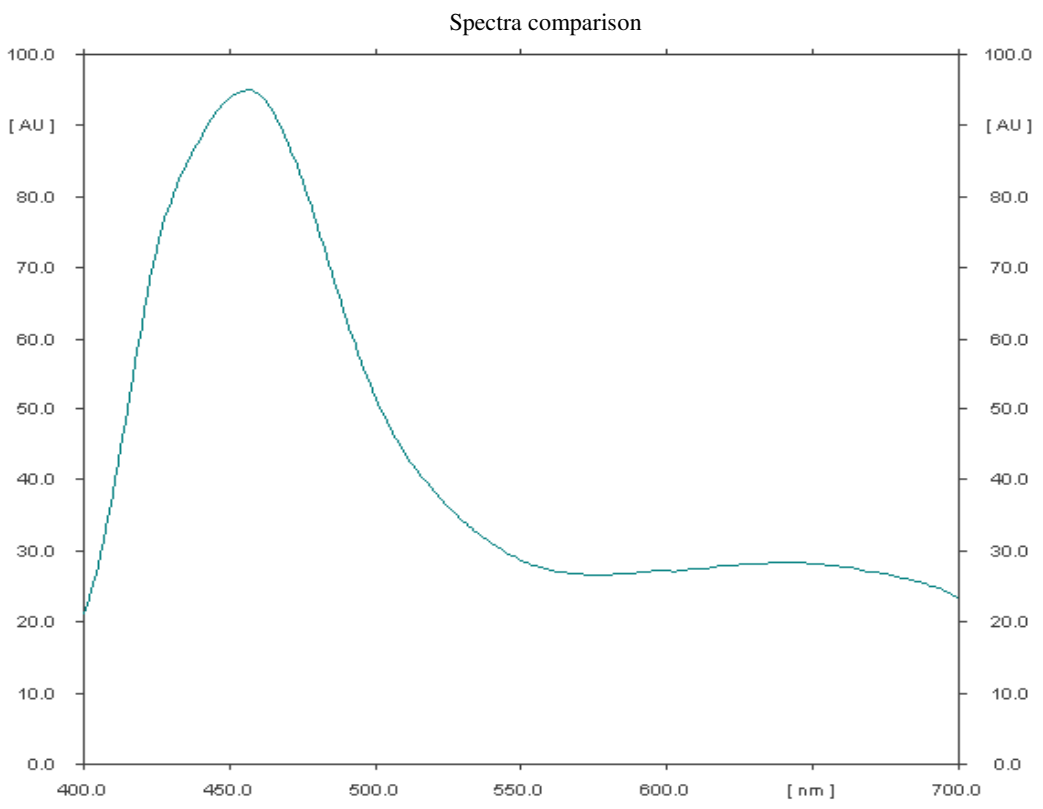

Figure 4. Absorbance spectrum of sucralose-rhodamine complex showing an absorbance maximum at $456 \mathrm{~nm}$ (Solvent system-I)

In absorbance mode at $456 \mathrm{~nm}$ LOD for this method was found to be $5-7 \mathrm{ng}$ where as in fluorescence mode at $366 \mathrm{~nm}$ it was found to be $4-5 \mathrm{ng}$. LOD for the two solvent systems was found to differ marginally. The method was found to be linear in the concentration range of 40 - $250 \mathrm{ng}$ with the correlation coefficients, $\mathrm{r}^{2}$ were better than 0.9881 (Table 1). 


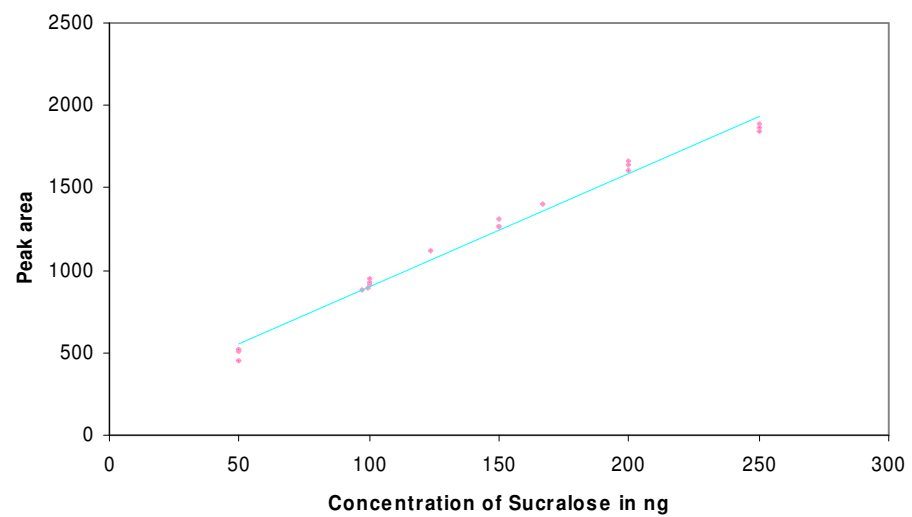

Figure 5. Linear calibration of sucralose derivatized with rhodamine-sulturic acid reagent $(y=6.0143 x+244.35)$ by peak area of absorbance measurement at $456 \mathrm{~nm}$ in the range between 50 and $250 \mathrm{ng}$ per band with relative standard deviation of the calibration plot \pm $2.3 \%$ and correlation coefficient $\mathrm{R}^{2}=0.9947$ (Solvent system-I).

Table 1. Comparison of the calibration data obtained for sucralose using two solvent systems after derivatization in different modes of measurement.

\begin{tabular}{cccc}
\hline Solvent System & Measurement mode & Regression equation & $\mathrm{R}^{2}$ \\
\hline I & Absorbance at $456 \mathrm{~nm}$ & $\mathrm{y}=6.0143 \mathrm{x}+244.35$ & 0.9947 \\
II & Absorbance at $456 \mathrm{~nm}$ & $\mathrm{y}=6.9029 \mathrm{x}+207.58$ & 0.9875 \\
I & Fluorescence at $366 \mathrm{~nm}$ & $\mathrm{y}=6.8169 \mathrm{x}+224.21$ & 0.9864 \\
II & Fluorescence at $366 \mathrm{~nm}$ & $\mathrm{y}=6.8255 \mathrm{x}+227.27$ & 0.9881 \\
\hline
\end{tabular}

The recovery data in cola drinks, lemon juices and sweets spiked with sucralose for solvent system- 1 and solvent system-2 at absorbance $456 \mathrm{~nm}$ and at fluorescence UV $366 \mathrm{~nm}$ shown (Table 2) to be better with relative standard deviation (RSD) less than $3(n=3)$. Where as data for commercially available dietetic samples were shown in Table 3.

Table 2. Data for recovery of sucralose in spiked samples obtained using two solvent systems after derivatization with rhodamine-sulfuric acid reagent in absorbance mode at 456 $\mathrm{nm}$ and in fluorescence mode at $366 \mathrm{~nm}$.

\begin{tabular}{|c|c|c|c|c|}
\hline \multirow{3}{*}{ Sample } & \multicolumn{4}{|c|}{ Recovery\% } \\
\hline & \multicolumn{2}{|c|}{ Solvent system 1} & \multicolumn{2}{|c|}{ Solvent system 2} \\
\hline & $\begin{array}{c}\text { Measurement } \\
\text { at } 456 \mathrm{~nm}\end{array}$ & $\begin{array}{c}\text { Measurement } \\
\text { at } 366 \mathrm{~nm}\end{array}$ & $\begin{array}{c}\text { Measurement } \\
\text { at } 456 \mathrm{~nm}\end{array}$ & $\begin{array}{c}\text { Measurement } \\
\text { at } 366 \mathrm{~nm}\end{array}$ \\
\hline \multicolumn{5}{|c|}{ (i) Sweet samples spiked with sucralose } \\
\hline $1 \mathrm{~g} \mathrm{~kg}^{-1}$ & 96 & 96.34 & 95.76 & 96.12 \\
\hline $1.5 \mathrm{~g} \mathrm{~kg}^{-1}$ & 94.21 & 95.01 & 94.09 & 94.59 \\
\hline $2 \mathrm{~g} \mathrm{~kg}^{-1}$ & 98.22 & 98.76 & 97.70 & 97.93 \\
\hline \multicolumn{5}{|c|}{ (ii) Cola drinks spiked with sucralose } \\
\hline $100 \mathrm{mg} \mathrm{L}^{-1}$ & 98.27 & 99.57 & 98.32 & 99.41 \\
\hline $80 \mathrm{mg} \mathrm{L}^{-1}$ & 98.12 & 98.79 & 96.51 & 97.01 \\
\hline $60 \mathrm{mg} \mathrm{L}^{-1}$ & 98.76 & 99.10 & 96.98 & 97.32 \\
\hline \multicolumn{5}{|c|}{ (iii) Lemon juices spiked with sucralose } \\
\hline $100 \mathrm{mg} \mathrm{L}^{-1}$ & 97.05 & 98.21 & 96.21 & 97.95 \\
\hline $80 \mathrm{mg} \mathrm{L}^{-1}$ & 98.32 & 99.12 & 97.77 & 98.09 \\
\hline $60 \mathrm{mg} \mathrm{L}^{-1}$ & 96.10 & 96.98 & 95.98 & 96.21 \\
\hline
\end{tabular}


Table 3. Data for recovery of sucralose in real samples obtained using two solvent systems after derivatization with rhodamine-sulfuric acid reagent in absorbance mode at $456 \mathrm{~nm}$ and in fluorescence mode at $366 \mathrm{~nm}$.

\begin{tabular}{|c|c|c|c|c|}
\hline Sample & $\mathrm{hR}_{\mathrm{f}}$ & $\begin{array}{l}\text { Amount of Sucralose } \\
\text { found, mg per } 1 \mathrm{~g}\end{array}$ & $\begin{array}{c}\mathrm{RSD} \% \\
(\mathrm{n}=3)\end{array}$ & $\begin{array}{c}\text { Label declaration, } \\
\text { mg per } 1 \mathrm{~g}\end{array}$ \\
\hline \multicolumn{5}{|c|}{ Mode: Measurement of Absorbance at $456 \mathrm{~nm}$. Solvent System-1 } \\
\hline Sugar free sweet & 62 & 1.24 & 2.5 & 1.5 \\
\hline Tabletop sweetener & 61 & 65.9 & 1.9 & 70 \\
\hline \multicolumn{5}{|l|}{ Solvent System-1I } \\
\hline Sugar free sweet & 45 & 1.235 & 2.3 & 1.5 \\
\hline Tabletop sweetener & 45 & 65.4 & 1.5 & 70 \\
\hline \multicolumn{5}{|c|}{ Mode: Measurement of Fluorescence at $366 \mathrm{~nm}$ Solvent System-1 } \\
\hline Sugar free sweet & 62 & 1.247 & 2.1 & 1.5 \\
\hline Tabletop sweetener & 61 & 66.4 & 2.0 & 70 \\
\hline \multicolumn{5}{|l|}{ Solvent System-1I } \\
\hline Sugar free sweet & 45 & 1.26 & 2.12 & 1.5 \\
\hline Tabletop sweetener & 45 & 68.3 & 2.08 & 70 \\
\hline
\end{tabular}

\section{Conclusion}

The method proposed for the determination of sucralose in tabletop sweeteners, cola drinks, lemon juices and sugar free sweets is simple, fast, sensitive, specific, reliable and selective when compared to the existing methods. Due to its capability of simultaneously handling multiple samples it can be adapted for use in pharmaceutical and food industries. Because of its high through put the method can also be used for routine work in food, drug, forensic and environmental regulatory laboratories.

\section{Acknowledgments}

One of the authors (MI) would like to thank, Dr. C.N. Bhattacharya, incharge-DirectorCum-Chief Forensic Scientist, Directorate of Forensic Science, Ministry of Home Affairs, Govt. of India for the research fellowship. Thanks are due to M/S Virchows Laboratory of Hyderabad (India) for supplying reference standards of sucralose.

\section{References}

1. Kobayashi C, Nakazato M, Yamajima Y, Ohno I, Kawano M and Yasuda K, J Food Hyg Soc Japan, 2001, 42, 139-143.

2. Kishi H and Kawana K, J Food Hyg Soc Japan, 2001, 42, 133-138.

3. Lawrence J F and Charbonneau C F, J Assoc off Anal Chem., 1988, 71, 934-937.

4. Shuko N, Mituso N, Yoko K, Ichiro T, Mitsuo O, Kazuo Y, Sukeji S, J Food Hyg Soc Japan, 2002, 43, 289-294.

5. Da-Jin Yang and Bo Chen, J Agric Food Chem., 2009, 57(8), 3022-3027.

6. Wasik A, Mccourt J, Buchgraber M, J Chrom A, 2007, 1157, 187-196.

7. Stroka J Dossi N and Anklam E, J Food Addit Contam., 2003, 20(6), 524-527.

8. Heinz M, Schreiter P and Baumann M, J Food Addit Contam., 2003, 20, 345-351.

9. Merlock G and Prabha S, J Agric Food Chem., 2007, 55, 7217-7223.

10. Spangenberg B, Stroka J, Arranz I and Anklam E, J Liquid Chromatogr Relat Technol., 2003, 26(16), 2729-2739.

11. Stroka J, Doncheva I and Spangenberg B, J Assoc off Anal Chem., 2009, 92(4), 1153-1159.

12. Merlock G E and Vega-Herrera M A, J Planar Chromatogr., 2007, 20, 411-417. 


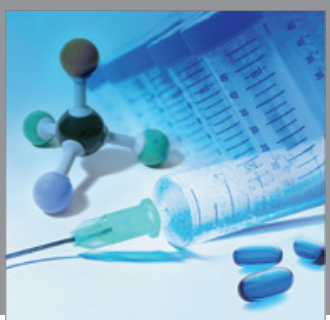

International Journal of

Medicinal Chemistry

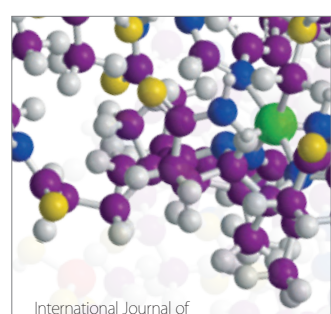

Carbohydrate Chemistry

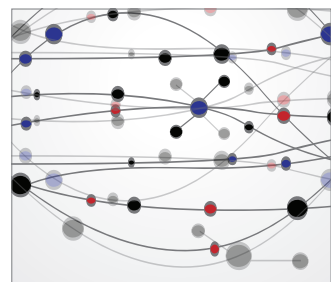

The Scientific World Journal
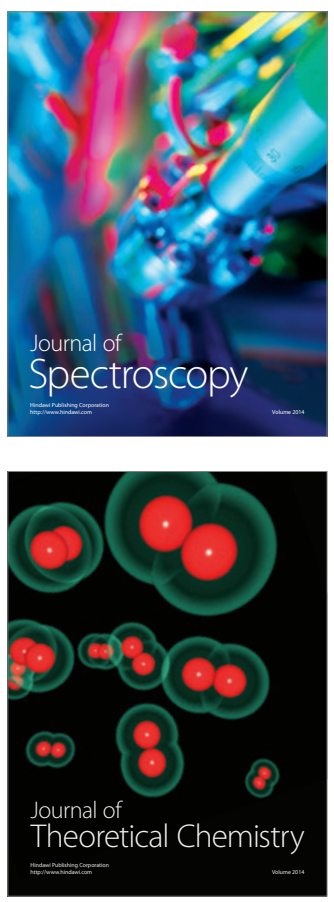
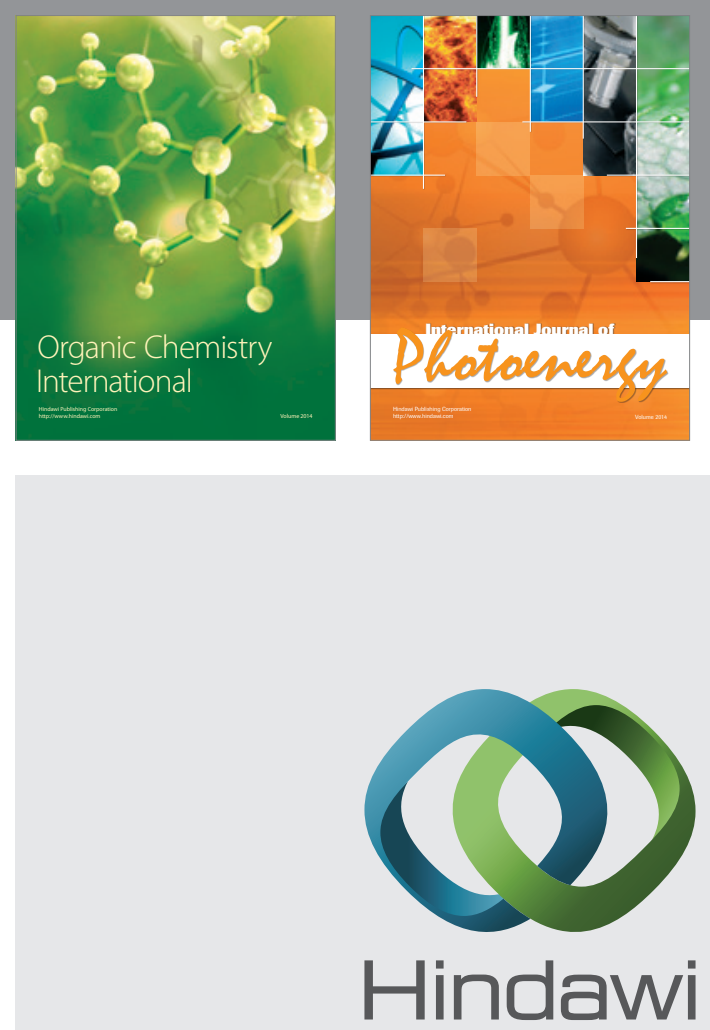

Submit your manuscripts at

http://www.hindawi.com
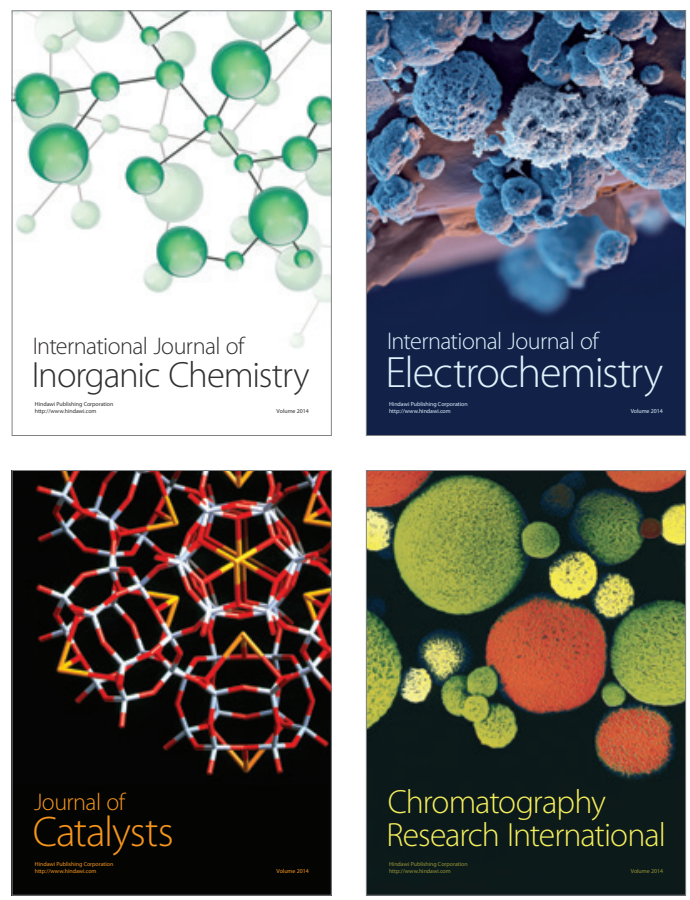
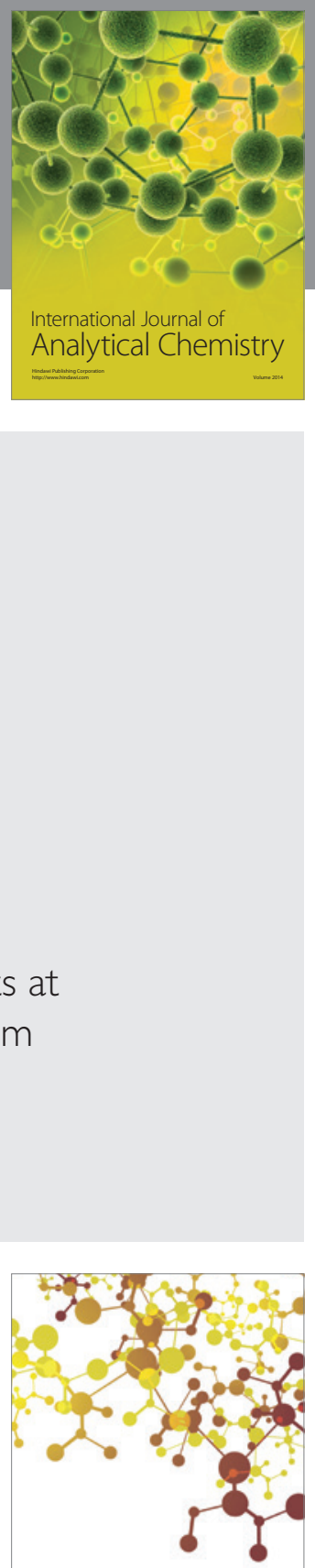

Journal of

Applied Chemistry
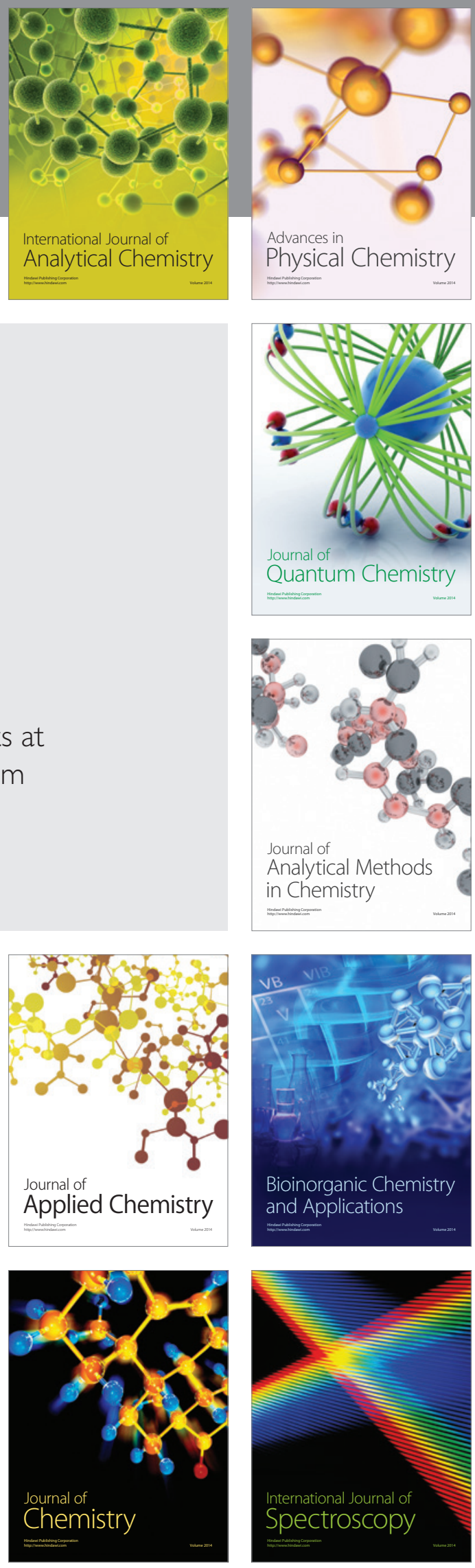